\title{
Elevated central venous pressure is associated with increased mortality and acute kidney injury in critically ill patients: a meta-analysis
}

\author{
Chuan-Yu Chen ${ }^{1}$, Yan Zhou ${ }^{1}$, Peng Wang ${ }^{1}$, En-Yao Qi ${ }^{1}$ and Wan-Jie Gu ${ }^{2^{*}}$ (D)
}

\begin{abstract}
Background: The association of central venous pressure (CVP) and mortality and acute kidney injury (AKI) in critically ill adult patients remains unclear. We performed a meta-analysis to determine whether elevated CVP is associated with increased mortality and AKI in critically ill adult patients.

Methods: We searched PubMed and Embase through June 2019 to identify studies that investigated the association between CVP and mortality and/or AKI in critically ill adult patients admitted into the intensive care unit. We calculated the summary odds ratio (OR) and $95 \% \mathrm{Cl}$ using a random-effects model.

Results: Fifteen cohort studies with a broad spectrum of critically ill patients (mainly sepsis) were included. On a dichotomous scale, elevated CVP was associated with an increased risk of mortality (3 studies; 969 participants; OR, 1.65; 95\% Cl, 1.19-2.29) and AKI (2 studies; 689 participants; OR, 2.09; 95\% Cl, 1.39-3.14). On a continuous scale, higher CVP was associated with greater risk of mortality (5 studies; 7837 participants; OR, 1.10; 95\% Cl, 1.03-1.17) and AKI (6 studies; 5446 participants; OR, 1.14; 95\% Cl, 1.06-1.23). Furthermore, per $1 \mathrm{mmHg}$ increase in CVP increased the odds of AKI by 6\% (4 studies; 5150 participants; OR, 1.06; 95\% Cl, 1.01-1.12). Further analyses restricted to patients with sepsis showed consistent results.
\end{abstract}

Conclusions: Elevated CVP is associated with an increased risk of mortality and AKI in critically ill adult patients admitted into the intensive care unit.

Trial registration: PROSPERO, CRD42019126381

Keywords: Central venous pressure, Mortality, Acute kidney injury, Critical illness

\section{Background}

Central venous pressure (CVP) is a local hemodynamic parameter determined by the interaction between venous return and cardiac function and used as a surrogate of intravascular volume [1]. Therefore, CVP measurements are often applied for assessing volume status and volume responsiveness to guide fluid resuscitation at the bedside in critically ill patients [2]. However, the validity of CVP in critical care settings has recently been challenged and the use of CVP measurements to direct volume management

\footnotetext{
* Correspondence: wanjiegu@hotmail.com

${ }^{2}$ Department of Anesthesiology, Nanjing Drum Tower Hospital, Medical College of Nanjing University, 321 Zhongshan Road, Nanjing 210008, China Full list of author information is available at the end of the article
}

has been reported unreliable [3]. Based on the rationale provided by the Starling curves and Guyton theory on cardiac function [4], high CVP may impede venous return to the heart and disturb microcirculatory blood flow which may harm organ function, lead to poor prognosis, and even increase mortality. Moreover, elevated CVP will particularly harm kidney hemodynamic and promote acute kidney injury (AKI) by imposing an increased "afterload" on the kidney [5]. However, the association between CVP and mortality and AKI in critically ill patients remains unclear.

So far, previous studies have evaluated the association of CVP and mortality and AKI in critically ill patients but have shown inconsistent results [6-20]. Thus, we performed a meta-analysis to investigate the association 
of elevated CVP and mortality and AKI in critically ill adult patients, hypothesizing that elevated CVP is associated with increased mortality and acute kidney injury in critically ill adult patients.

\section{Materials}

\section{Protocol and registration}

This meta-analysis was reported in compliance with the PRISMA statement [21]. The protocol was registered on PROSPERO (CRD42019126381). The full details of the protocol are available on request.

\section{Literature search}

Studies were identified by searching electronic databases including PubMed and Embase. No limits were applied for language. We used controlled vocabulary $(\mathrm{MeSH}$ in PubMed and Emtree in Embase) and keywords as search terms. The last search was run on June 2019. The full details of the search strategy are available (Additional file 1). In addition, we hand-searched the reference lists of eligible studies.

\section{Selection criteria}

We carried out the initial search, deleted duplicate records, screened the titles and abstracts for relevance, and identified records as included, excluded, or uncertain. In case of uncertainty, the full-text article was acquired to identify eligibility. Studies were eligible for inclusion if they met the following criteria: type of participants, critically ill adult patients admitted into intensive care unit (ICU); type of exposure, CVP; type of outcome, mortality or AKI, defined as individual study (Additional file 2); and types of studies, cohort studies.

\section{Data extraction}

We developed a data extraction sheet in standardized Excel (Microsoft Corporation). One author extracted the following data from included studies and the second author checked the extracted data. The following information was extracted from each study: author, year, country, population, timing of CVP measurement, CVP category, sample size, proportion of mechanical ventilation, event rate, multivariate-adjusted risk estimates, outcomes, study design, and covariates in the fully adjusted model. Any discrepancy was resolved by discussion and consensus.

\section{Quality assessment}

We evaluated the quality of included studies by using the Newcastle-Ottawa scale [22], which is a scale for assessing the quality of observational studies in meta-analyses. This scale awards a maximum of nine stars to each study: four stars for selection of participants and measurement of exposure, two stars for comparability, and three stars for assessment of outcomes and adequacy of follow-up. We assigned scores of 0-3, 4-6, and 7-9 for low, moderate, and high quality of studies, respectively.

\section{Statistical analysis}

The meta-analyses were performed by computing odds ratios (ORs) with 95\% CIs for mortality and AKI using a random-effects model, accounting for clinical heterogeneity. Heterogeneity across studies was assessed by using the Q statistic with its $P$ value and $I^{2}$ statistic [23]. The $I^{2}$ statistics used to quantify the proportion of total variation in the effect estimation that is due to between-study variations. An $I^{2}>50 \%$ indicates significant heterogeneity [24]. A two-sided $P<0.05$ was considered statistically significant. All analyses were performed using Stata statistical software version 13.0 (StataCorp, USA).

\section{Results}

Study selection

We identified 2048 records in the initial search. After adjusting for duplicates 1700 remained. Of these, 1672 records were discarded because it appeared that these papers clearly did not meet the criteria after reviewing the titles and abstracts. The full text of the remaining 28 articles was examined in more detail. After application of the inclusion criteria, 15 studies were included in the meta-analysis (Fig. 1) [6-20].

\section{Study characteristics}

The characteristics of the included studies are presented in Table 1. These studies were published between 2004 and 2019. The sample size of the individual study ranges from 39 to 4761 . The population involved a broad spectrum of critically ill patients (mainly sepsis). CVP category was based on a dichotomous scale and a continuous scale. Adjusted estimates could be determined for almost all studies even though the adjusted factors were slightly different (Additional file 2). Six studies were prospective cohort and the remaining 9 studies were retrospective cohort. Details of the quality assessment of included studies are outlined (Additional file 3). The score for each study was 7 or above, suggesting that all the studies were of high quality.

\section{CVP as a dichotomous scale and mortality and AKI in critically ill patients}

On a dichotomous scale, elevated CVP was associated with increased risk of mortality (3 studies; 969 participants; OR, 1.65; 95\% CI, 1.19-2.29; $P=0.003 ; I^{2}=35.5 \%$; Fig. 2) and AKI (2 studies; 689 participants; OR: 2.09; 95\% CI, 1.39-3.14; $P<0.001 ; I^{2}=0.0 \%$; Fig. 2).

\section{CVP as a continuous scale and mortality and AKI in critically ill patients}

On a continuous scale, higher CVP was associated with greater risk of mortality (5 studies; 7837 participants; OR, 


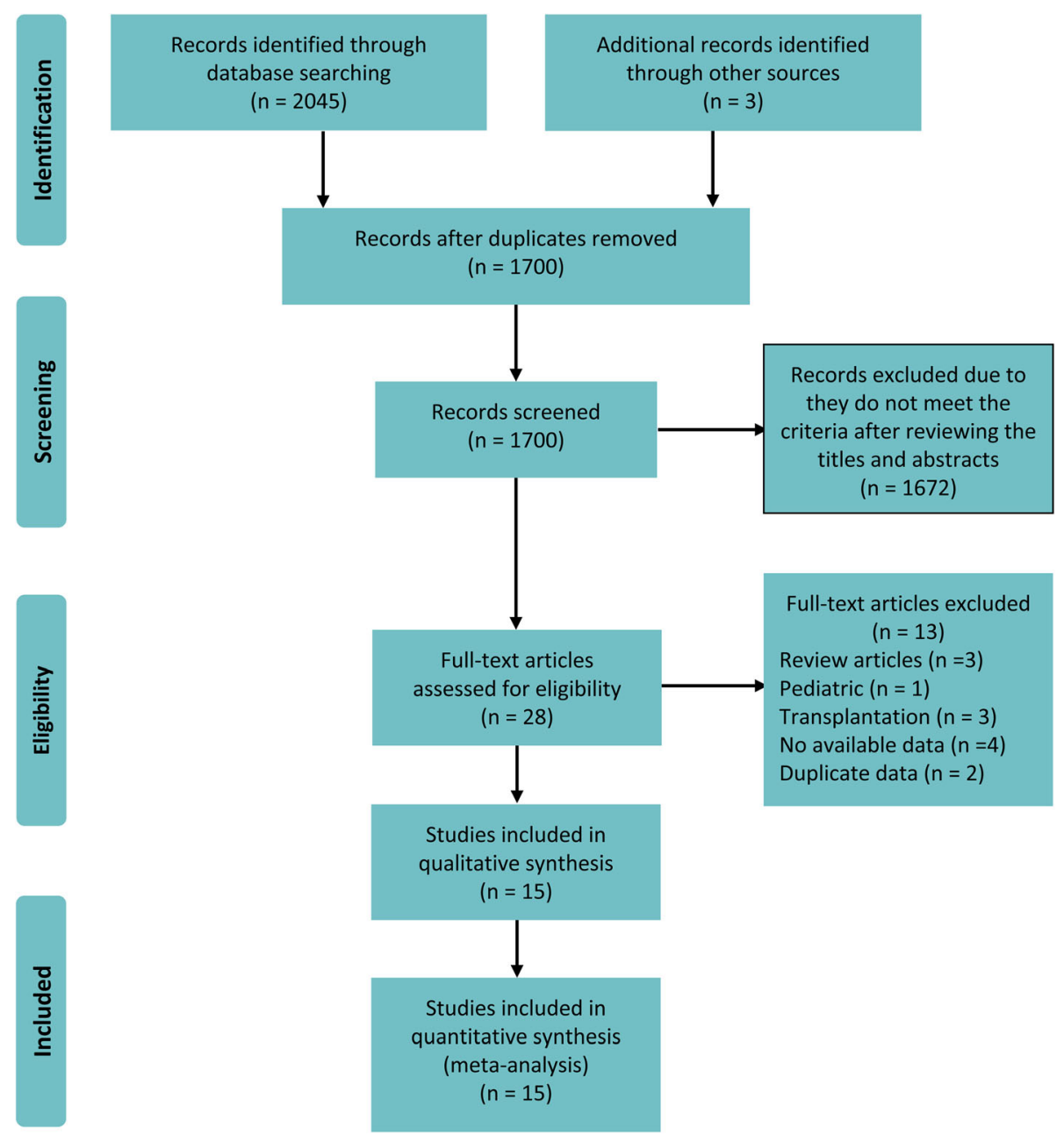

Fig. 1 Preferred Reporting Items for Systematic Reviews and Meta-Analyses Flow Diagram

1.10; 95\% CI, 1.03-1.17; $P=0.006 ; I^{2}=77.3 \%$; Fig. 3$)$ and AKI (6 studies; 5446 participants; OR, 1.14; 95\% CI, 1.061.23; $P<0.001 ; I^{2}=86.1 \%$; Fig. 3$)$.

\section{CVP increase in per $1 \mathrm{mmHg}$ and mortality and AKI in critically ill patients}

No study reported CVP increase in per $1 \mathrm{mmHg}$ and risk of mortality. Four studies with 5150 participants reported CVP increase in per $1 \mathrm{mmHg}$ and risk of AKI. The results suggested that per $1 \mathrm{mmHg}$ increase in CVP increased the odds of AKI by $6 \%$ (OR, 1.06; 95\% CI, 1.01-1.12; $P=0.022$; $I^{2}=75.7 \%$; Fig. 4).

\section{Further analyses on CVP and mortality and AKI in patients with sepsis}

Three studies with 969 participants reported the association between elevated CVP and risk of mortality on a dichotomous scale. The results suggested that elevated CVP was associated with increased risk of mortality (OR, 1.65; 95\% CI, 1.19-2.29; $P=0.003 ; I^{2}=35.5 \%$; Additional file 4).
Three studies with 501 participants reported the association between elevated CVP and risk of AKI on a continuous scale. The results suggested that higher CVP was associated with greater risk of AKI (OR, 1.32; 95\% CI, 1.16-1.49; $P<0.001 ; I^{2}=41.3 \%$; Additional file 5). Furthermore, per $1 \mathrm{mmHg}$ increase in CVP increased the odds of AKI by 23\% (2 studies; 244 participants; OR, 1.23; 95\% CI, 1.11-1.38; $P<0.001 ; I^{2}=0.0 \%$; Additional file 6).

\section{Discussion}

Main findings

To our knowledge, this is the first meta-analysis to investigate the association between elevated CVP and the risk of mortality and AKI in critically ill adult patients. The two principal findings are summarized: elevated CVP is associated with increased risk of mortality and AKI in critically ill adult patients; per $1 \mathrm{mmHg}$ increase in CVP increases the odds of AKI in critically ill adult patients. Further analyses restricted to patients with sepsis showed consistent results. 


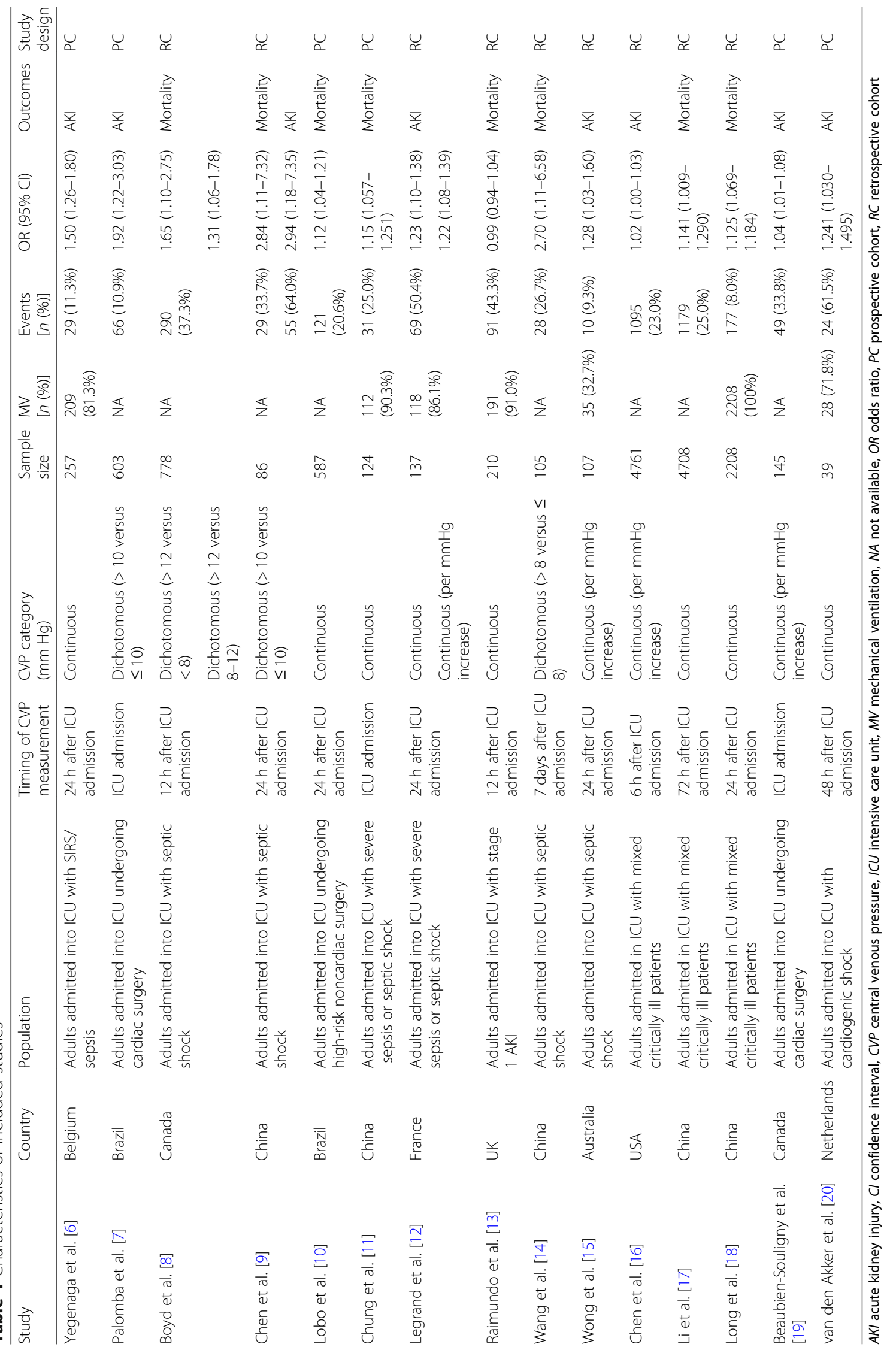




\begin{tabular}{|c|c|c|c|}
\hline \multicolumn{2}{|l|}{ Study } & \multirow[b]{2}{*}{ OR $(95 \% \mathrm{Cl})$} & \multirow{2}{*}{$\begin{array}{l}\% \\
\text { Weight }\end{array}$} \\
\hline ID & & & \\
\hline \multicolumn{4}{|l|}{ Mortality } \\
\hline Boyd 2011 ( >12mmHg versus < $8 \mathrm{mmHg}$ ) & - & $1.65(1.10,2.75)$ & 29.57 \\
\hline Boyd 2011 (>12mmHg versus 8-12mmHg) & $\rightarrow$ & $1.31(1.06,1.78)$ & 48.80 \\
\hline Chen 2011 (>10mmHg versus $\leq 10 \mathrm{mmHg}$ ) & & $2.84(1.11,7.32)$ & 10.28 \\
\hline Wang $2015(>8 \mathrm{mmH}$ g versus $\leq 8 \mathrm{mmHg})$ & & $2.70(1.11,6.58)$ & 11.35 \\
\hline Subtotal (1-squared $=35.5 \%, \mathrm{p}=0.199$ ) & & $1.65(1.19,2.29)$ & 100.00 \\
\hline \multicolumn{4}{|l|}{ AKI } \\
\hline Palomba $2007(>10 \mathrm{mmHg}$ versus $\leq 10 \mathrm{mmHg}$ ) & & $1.92(1.22,3.03)$ & 80.17 \\
\hline Chen 2011 (>10mmHg versus $\leq 10 \mathrm{mmHg}$ ) & & $2.94(1.18,7.35)$ & 19.83 \\
\hline Subtotal (I-squared $=0.0 \%, p=0.414$ ) & & $2.09(1.39,3.14)$ & 100.00 \\
\hline \multicolumn{4}{|l|}{ NOTE: Weights are from random effects analysis } \\
\hline T & & & \\
\hline
\end{tabular}

Fig. 2 The association of CVP (on a dichotomous scale) and mortality and AKI in critically ill adult patients. Cl, confidence interval; OR, odds ratio

\section{Possible mechanisms for findings}

CVP is a pressure recorded from the superior vena cava or the right atrium, which represents the pressure index of cardiac preload and is equal to the end-diastolic pressure of the right ventricle in the absence of tricuspid stenosis [25].
It is determined by the interaction between cardiac function and venous return. The CVP is a complex interplay influenced by right ventricular function, right ventricular afterload, right ventricular compliance, venous tone, volume status, abdominal pressure, intrathoracic pressure (mean

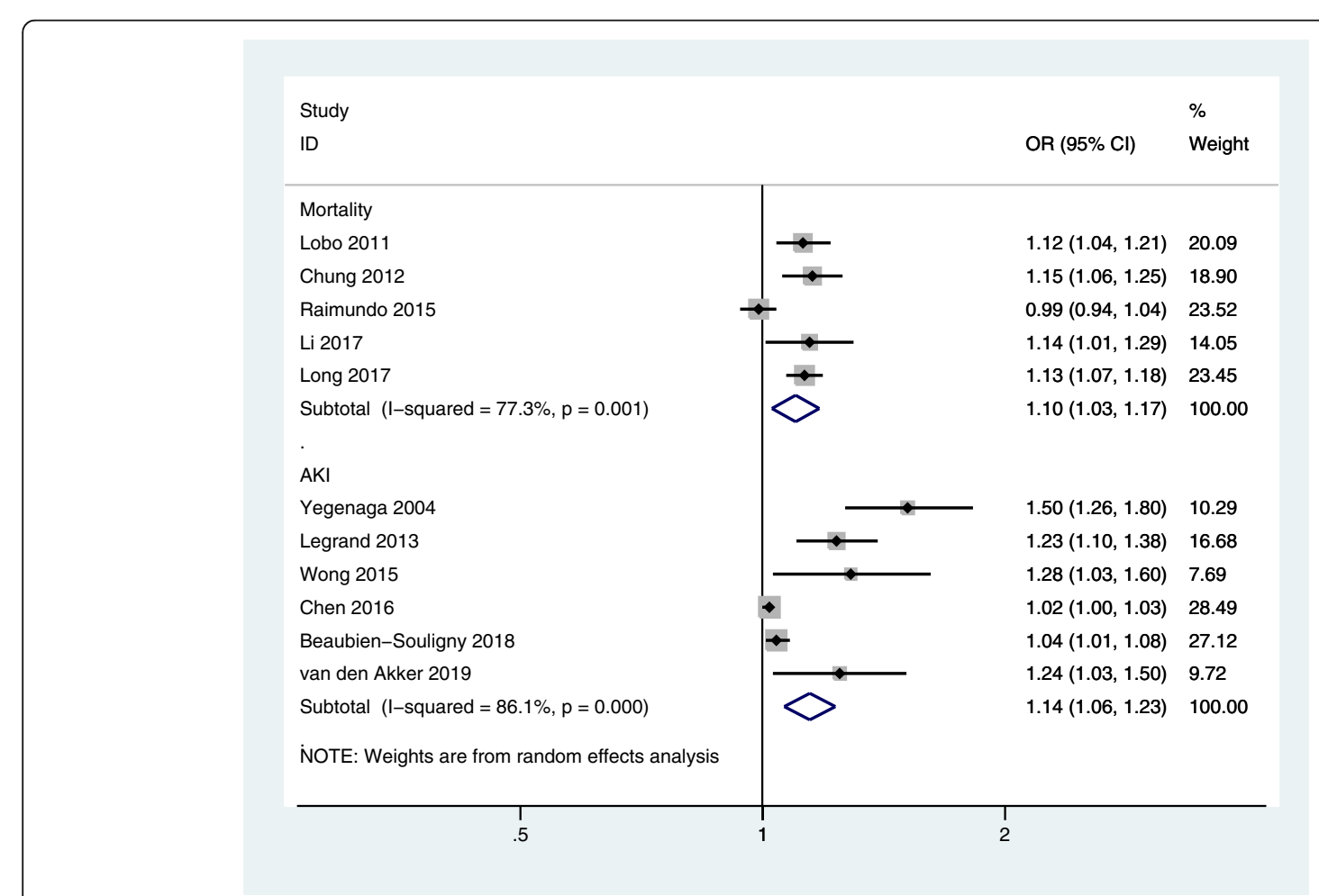

Fig. 3 The association of CVP (on a continuous scale) and mortality and AKI in critically ill adult patients. Cl, confidence interval; OR, odds ratio 


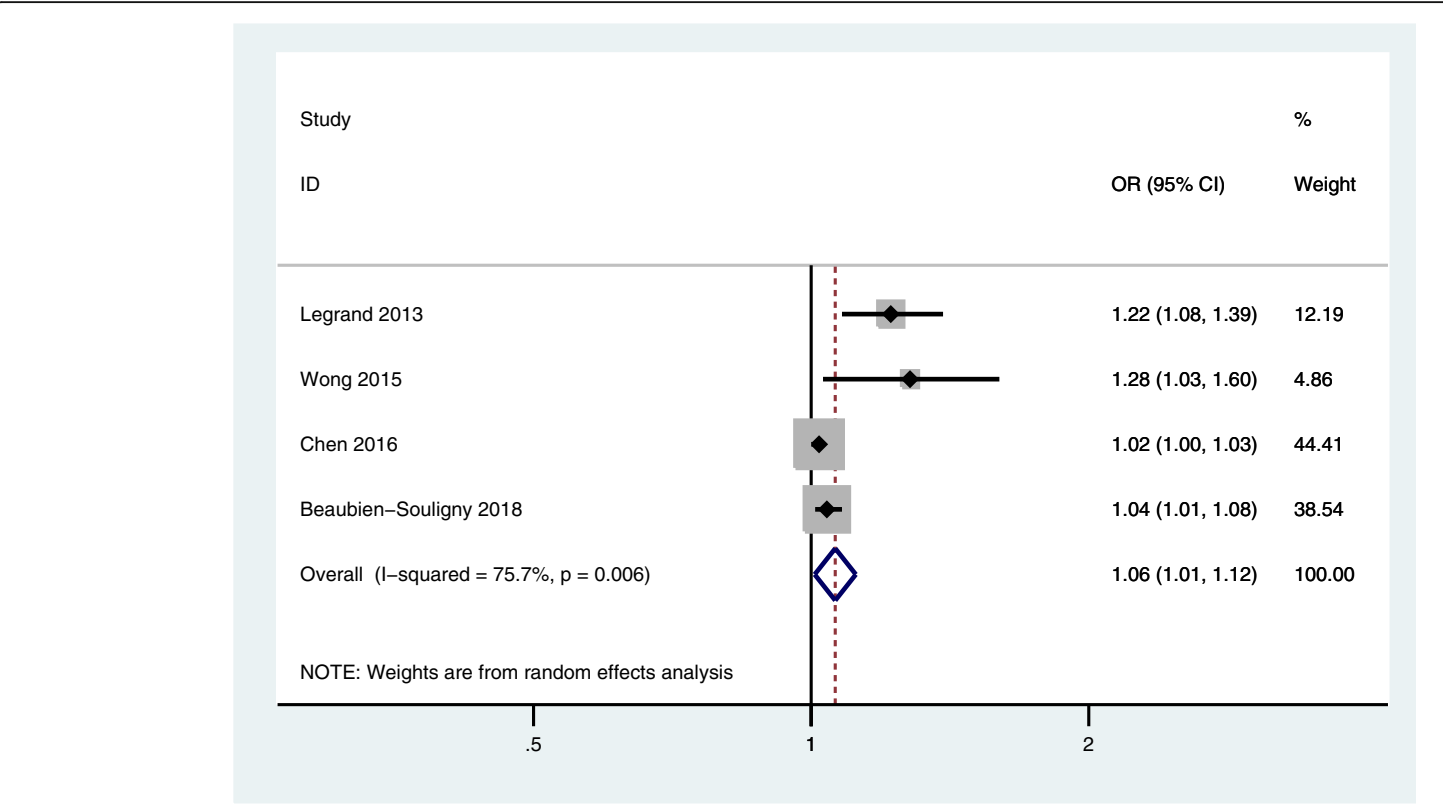

Fig. 4 The association of CVP (per $1 \mathrm{mmHg}$ increase) and AKI in critically ill adult patients. Cl, confidence interval; OR, odds ratio

airway pressure), and many other factors [26]. According to Guyton's venous reflux theory, cardiac out equals venous return and venous reflux is dependent on mean circulatory filling pressure (MCFP) and CVP gradient (i.e., MCFPCVP) [4]. Contrary to the misleading assertion that high CVP represents an increase in cardiac output, excessive fluid administration which just leading to an increase of CVP but does not increase cardiac output when the venous return curve intersects this area of the cardiac function curve [26]. This is mainly because fluid loading only increases right atrial pressure/CVP and tissue edema, but does not significantly increase end-diastolic volume and stroke volume on this condition. When CVP increased or MCFP decreased, venous reflux decreased; on the contrary, venous reflux increased if CVP decreased or MCFP increased $[27,28]$. Therefore, lower CVP is needed to ensure venous reflux and cardiac output if MCFP in the flat part of the Starling curve.

Traditionally, renal injury is considered to be caused by reduced renal perfusion due to decreased cardiac output or vascular volume [29]. Renal perfusion pressure, defined as mean arterial pressure minus renal venous pressure, is a potential risk factor for AKI progression in critically ill patients [30]. A high CVP is transmitted backwards increasing renal venous pressure, which reduces renal perfusion pressure and increases renal venous congestion [31]. These two factors undependably have profound effects on renal perfusion and renal function and further leading to AKI [32].

\section{Implications for clinical practice}

Our findings have important implications for clinicians to some extent. Almost all patients undergoing major surgery, as well as patients admitted to ICU, will receive CVP monitoring. A normal CVP in a healthy individual is 0-2 $\mathrm{mmHg}$. Legrand et al. found a liner relationship between CVP and the probability of AKI, and increasing the CVP from above $2 \mathrm{mmHg}$ is associated with an increased risk of AKI [12]. In line with this study, our meta-analysis found that per $1 \mathrm{mmHg}$ increase in CVP increases the odds of AKI in critically ill adult patients. It is generally believed that low CVP represents volume depletion and high CVP indicates volume overload; thus, CVP is usually used to make decisions regarding fluid therapy. In fact, to use CVP as a measure of intravascular volume or to define volume responsiveness or the cardiac output response to volume challenges is not only unreliable but also potentially dangerous. In clinical practice, titrating fluid therapy to the CVP is fraught with danger and CVP alone should never be used to make decisions regarding fluid therapy. At the bedside, CVP should be a stopping rule, not a target of fluid resuscitation [33].

\section{Strengths and limitations}

The strength of this meta-analysis lies in compliance with the PRISMA statement and registration on PROSPERO with protocol. Our meta-analysis also has a major limitation that affects the interpretation of the results. The metaanalysis included a broad spectrum of critically ill patients with wide variability. Moreover, there is difference in CVP category, definition of mortality and AKI, and study design. These factors may introduce the heterogeneity and could affect the results. Nevertheless, we used a random-effects model to pool the most fully adjusted estimates, which could reduce the confounding bias in the results. 


\section{Conclusions}

Elevated CVP is associated with an increased risk of mortality and AKI in critically ill adult patients admitted into the intensive care unit.

\section{Supplementary information}

Supplementary information accompanies this paper at https://doi.org/10. 1186/s13054-020-2770-5.

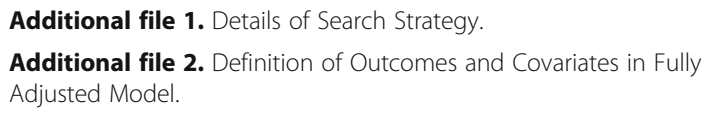

Additional file 3. Quality Assessment of Included Studies by NewcastleOttawa Scales.

Additional file 4. The association of CVP (on a dichotomous scale) and mortality in patients with sepsis.

Additional file 5. The association of CVP (on a continuous scale) and AKI in patients with sepsis.

Additional file 6. The association of CVP (per $1 \mathrm{mmHg}$ increase) and AKI in patients with sepsis.

\section{Abbreviations}

AKI: Acute kidney injury; Cl: Confidence interval; CVP: Central venous pressure; OR: Odds ratio; PRISMA: Preferred Reporting Items for Systematic Reviews and Meta-Analyses

\section{Acknowledgements}

Not applicable

\section{Authors' contributions}

CYC contributed to the conception and design of the study, acquisition of data, analysis and interpretation of data, drafting the article, and final approval of the version to be published. YZ, PW, and EYQ contributed to the acquisition of data, analysis and interpretation of data, drafting the article, and final approval of the version to be published. WJG contributed to the conception and design of the study, analysis and interpretation of data drafting and revising the article, and final approval of the version to be published.

\section{Funding}

None

Availability of data and materials

Not applicable

\section{Ethics approval and consent to participate}

Not applicable

\section{Consent for publication}

Not applicable

\section{Competing interests}

The authors declare that they have no competing interests.

\section{Author details}

'Department of Anesthesiology, Luhe People's Hospital of Nanjing, 9 Jiankang Road, Nanjing 211500, China. 'Department of Anesthesiology, Nanjing Drum Tower Hospital, Medical College of Nanjing University, 321 Zhongshan Road, Nanjing 210008, China.

Received: 30 October 2019 Accepted: 10 February 2020

Published online: 05 March 2020

\section{References}

1. Marik PE, Baram M, Vahid B. Does central venous pressure predict fluid responsiveness? A systematic review of the literature and the tale of seven mares. Chest. 2008;134:172-8.
2. Marik PE, Cavallazzi R. Does the central venous pressure predict fluid responsiveness? An updated meta-analysis and a plea for some common sense. Crit Care Med. 2013;41:1774-81.

3. Ho KM. Pitfalls in haemodynamic monitoring in the postoperative and critical care setting. Anaesth Intensive Care. 2016;44:14-9.

4. Magder S. Bench-to-bedside review: an approach to hemodynamic monitoring--Guyton at the bedside. Crit Care. 2012;16:236.

5. Chen X, Wang X, Honore PM, Spapen HD, Liu D. Renal failure in critically ill patients, beware of applying (central venous) pressure on the kidney. Ann Intensive Care. 2018:8:91

6. Yegenaga I, Hoste E, Van Biesen W, Vanholder R, Benoit D, Kantarci G, Dhondt A, Colardyn F, Lameire N. Clinical characteristics of patients developing ARF due to sepsis/systemic inflammatory response syndrome: results of a prospective study. Am J Kidney Dis. 2004;43:817-24

7. Palomba H, de Castro I, Neto AL, Lage S, Yu L. Acute kidney injury prediction following elective cardiac surgery: AKICS score. Kidney Int. 2007;72:624-31.

8. Boyd JH, Forbes J, Nakada TA, Walley KR, Russell JA. Fluid resuscitation in septic shock: a positive fluid balance and elevated central venous pressure are associated with increased mortality. Crit Care Med. 2011;39:259-65.

9. Chen XK, Li SW, Liu DW, Yang RL, Zhang HM, Zhang H, Wang XT, Chai WZ. Effects of central venous pressure on acute kidney injury in septic shock. Zhonghua Yi Xue Za Zhi. 2011;91:1323-7.

10. Lobo SM, Rezende E, Knibel MF, Silva NB, Páramo JA, Nácul FE, Mendes CL, Assunção M, Costa RC, Grion CC, Pinto SF, Mello PM, Maia MO, Duarte PA, Gutierrez F, Silva JM Jr, Lopes MR, Cordeiro JA, Mellot C. Early determinants of death due to multiple organ failure after noncardiac surgery in high-risk patients. Anesth Analg. 2011;112:877-83.

11. Chung KP, Chang HT, Huang YT, Liao CH, Ho CC, Jerng JS, Yu CJ. Central venous oxygen saturation under non-protocolized resuscitation is not related to survival in severe sepsis or septic shock. Shock. 2012;38:584-91.

12. Legrand M, Dupuis C, Simon C, Gayat E, Mateo J, Lukaszewicz AC, Payen D. Association between systemic hemodynamics and septic acute kidney injury in critically ill patients: a retrospective observational study. Crit Care. 2013;17:R278.

13. Raimundo M, Crichton S, Syed Y, Martin JR, Beale R, Treacher D, Ostermann M. Low systemic oxygen delivery and BP and risk of progression of early AKI. Clin J Am Soc Nephrol. 2015:10:1340-9.

14. Wang XT, Yao B, Liu DW, Zhang HM. Central venous pressure dropped early is associated with organ function and prognosis in septic shock patients: a retrospective observational study. Shock. 2015;44:426-30.

15. Wong BT, Chan MJ, Glassford NJ, Mårtensson J, Bion V, Chai SY, Oughton C, Tsuji IY, Candal CL, Bellomo R. Mean arterial pressure and mean perfusion pressure deficit in septic acute kidney injury. J Crit Care. 2015:30:975-81.

16. Chen KP, Cavender S, Lee J, Feng M, Mark RG, Celi LA, Mukamal KJ, Danziger J. Peripheral edema, central venous pressure, and risk of AKI in critical illness. Clin J Am Soc Nephrol. 2016;11:602-8.

17. Li DK, Wang XT, Liu DW. Association between elevated central venous pressure and outcomes in critically ill patients. Ann Intensive Care. 2017;7:83.

18. Long Y, Su L, Zhang Q, Zhou X, Wang H, Cui N, Chai W, Wang X, Rui X, Liu D. Elevated mean airway pressure and central venous pressure in the first day of mechanical ventilation indicated poor outcome. Crit Care Med. 2017;45:e485-92.

19. Beaubien-Souligny W, Benkreira A, Robillard P, Bouabdallaoui N, Chassé M, Desjardins G, Lamarche Y, White M, Bouchard J, Denault A. Alterations in portal vein flow and intrarenal venous flow are associated with acute kidney injury after cardiac surgery: a prospective observational cohort study. J Am Heart Assoc. 2018;7:e009961.

20. van den Akker JPC, Bakker J, Groeneveld ABJ, den Uil CA. Risk indicators for acute kidney injury in cardiogenic shock. J Crit Care. 2019;50:11-6.

21. Liberati A, Altman DG, Tetzlaff J, Mulrow C, Gøtzsche PC, loannidis JP, Clarke M, Devereaux PJ, Kleijnen J, Moher D. The PRISMA statement for reporting systematic reviews and meta-analyses of studies that evaluate health care interventions: explanation and elaboration. J Clin Epidemiol. 2009:62:e1-34.

22. Wells GA, Shea B, O'Connell D, Peterson J, Welch V, Losos M, Tugwell P. The Newcastle-Ottawa scale (NOS) for assessing the quality of nonrandomized studies in meta-analysis. Ottawa Hospital Research Institute website http://www. ohri.ca/programs/dinical_epidemiology/oxford.asp. Accessed 28 Oct 2019.

23. Higgins JP, Thompson SG, Deeks JJ, Altman DG. Measuring inconsistency in meta-analyses. BMJ. 2003;327:557-60.

24. Higgins JP, Thompson SG. Quantifying heterogeneity in a meta-analysis. Stat Med. 2002:21:1539-58.

25. Wang X, Chen H, Liu D, Zhang Q, Su L. The correlation between CVPderived parameters and the prognosis of critically ill patients. J Crit Care. 2017:40:257-64 
26. Gelman S. Venous function and central venous pressure: a physiologic story. Anesthesiology. 2008;108:735-48.

27. Brengelmann GL. A critical analysis of the view that right atrial pressure determines venous return. J Appl Physiol. 2003;94:849-59.

28. Beard DA, Feigl EO. Understanding Guyton's venous return curves. Am J Physiol Heart Circ Physiol. 2011;301:H629-33.

29. Ljungman S, Laragh JH, Cody RJ. Role of the kidney in congestive heart failure. Relationship of cardiac index to kidney function. Drugs. 1990;39:10-21.

30. Ostermann M, Hall A, Crichton S. Low mean perfusion pressure is a risk factor for progression of acute kidney injury in critically ill patients - a retrospective analysis. BMC Nephrol. 2017;18:151.

31. Mullens W, Abrahams Z, Francis GS, Sokos G, Taylor DO, Starling RC, Young $J B$, Tang WHW. Importance of venous congestion for worsening of renal function in advanced decompensated heart failure. J Am Coll Cardiol. 2009; 53:589-96.

32. Prowle JR, Bellomo R. Fluid administration and the kidney. Curr Opin Crit Care. 2010;16:332-6.

33. Pinsky MR, Kellum JA, Bellomo R. Central venous pressure is a stopping rule, not a target of fluid resuscitation. Crit Care Resusc. 2014;16:245-6.

\section{Publisher's Note}

Springer Nature remains neutral with regard to jurisdictional claims in published maps and institutional affiliations.

Ready to submit your research? Choose BMC and benefit from:

- fast, convenient online submission

- thorough peer review by experienced researchers in your field

- rapid publication on acceptance

- support for research data, including large and complex data types

- gold Open Access which fosters wider collaboration and increased citations

- maximum visibility for your research: over $100 \mathrm{M}$ website views per year

At $\mathrm{BMC}$, research is always in progress.

Learn more biomedcentral.com/submissions 